\title{
Research on Application of Network Technology on College Physical
}

\section{Education}

\author{
Xiaobao Zhang $^{1}$, Zhen Tan ${ }^{1}$ \\ ${ }^{1}$ Nanchang Institute of Science and Technology, Nanchang, Jiangxi, 330108 \\ 346591653@163.com
}

KEYWORDS: College Physical Education; Learning Technology; Application Measures

\begin{abstract}
With the deepening of the new curriculum, learning technology to be widely used, not only greatly enhance the efficiency of classroom teaching in Universities, but also to encourage students to get a more comprehensive development. Therefore we can say technology for online education teaching has a very important significance, even in college physical education, its role is obvious. This paper analyzes the network of educational technology in the moment of College Physical Education existence value, and on this basis discusses the specific application of network technology education in college physical education, hoping to provide a reference for Physical Education in Colleges and Universities.
\end{abstract}

\section{Introduction}

College Physical Education affects not only the physical health of students, as well as a direct impact on the ability of students in all aspects. In today's evolving social situation, the industry increasingly high demand for talent, corresponding to College Physical Education also put forward higher requirements. Online education technology to the college physical education not only benefits educational level is improved, while largely improve teaching efficiency. In Higher Education during the network education technology, teaching is the moment a very important field of education reform and development, it has the significance is very important.

\section{Significance of College Physical Education Teaching learning technology}

\section{A. Enhance the efficiency of teaching Physical Education in College}

With the deepening of the new curriculum reform and development, more and more colleges and universities will begin to use online education technology in the college physical education, not only for the rich teaching resources effectively Universities, Colleges and Universities to give prompting sports teaching content development, while giving College PE teaching structure has been further improved to promote the teaching efficiency has been improved. For now, many colleges and universities in our country during the elective sports, education and many other aspects of performance reporting, etc., are widely used since the beginning of internet, of which there are even some colleges and universities have begun by means of network technology to assist college physical education, sports establishment wilderness survival exercise. One of the most representative of the nature of the Yanshan, Shenzhen and Hunan University. From the point of view of teaching object, the same conditions of teachers, teaching during the use of network 
technology to implement secondary education, it can get to sports and special theoretical study theoretical knowledge more efficient than traditional teaching methods to give, so teaching to enhance efficiency. In addition, by network technology assisted instruction can be more convenient to the students, so that students anywhere can learn sports content, but also to allow students to study or repeatedly jumping learning. Thus, with respect to the traditional sports teaching, the sports network teaching allows students to master effective teaching and add content.

\section{B. Teaching objectives effectively complete}

College Physical Education where the main purpose is to allow students to sports and lifelong learning be promoted and enhanced sports consciousness, more comprehensive development of personnel trained to. According to the relevant studies have shown that practice, network technology applied to education in college physical education can be more convenient to integrate the use of teaching resources, student health knowledge and ability to make the Internet to get effective training, encourage college students to adapt to the overall level and capacity of the community would be enhanced. Furthermore, through the use of learning technology, learning to share network resources, so that independent learning space can be extended, but also to cultivate students' ability to learn independently, to promote and establish the sports consciousness of students and the establishment of a comprehensive and balanced development goals, so that teaching target can be more efficient implementation.

\section{Promote the college students' comprehensive and balanced development}

In College Physical Education Teaching learning technology, allows students to be more proactive to participate in sports activities to enhance the comprehensive evaluation of the results, therefore, the network technology into college physical education teaching, allowing students to get a more comprehensive and balanced development]. Under the current learning technology more popular social background, to enable it to assist the traditional classroom, allowing students to exercise consciousness and habit of constantly upgrading, but also to make it more profound understanding of the lifelong sports consciousness. With the rising consciousness of students of physical exercise, and also to better enable students to enhance physical fitness and sports goals are achieved robust boldness. Furthermore, in this teaching mode allows learning in their spare time can also learn sports knowledge and sports skills that students develop the habit of regular physical exercise has a great role in promoting.

\section{College of Physical Education Specific Application Method of Online Education Technology}

\section{A. Used in sports teaching in the network}

In Higher Education in the form of education network application technology is mainly reflected in the secondary teaching. On the moment, the Physical Education Model in Chinese Universities still is the traditional mode of teaching, there is great difficulty want to reform it, so in Higher Education in the form of network technology only asynchronous teaching, traditional teaching just in terms of the corresponding play a supporting role. For example: Many of our colleges and universities, campus network by means of technology, the use of computer networks for teaching sports management. And the use of network management to control the progress of teaching, allowing design effectively grasp the teaching hours, so that students registered user name can log on to the website of Physical Education, which will be able to directly interact with information and 
teachers. By means of a network management program that allows network technology and its unique advantages into full play, the students use "credit card" approach to class, so students will be able to conduct automatic registration class, the teacher let the class, the students can grasp the situation more . Additionally, the computer is also able to carry out regular student achievement statistics, student achievement is qualified can automatically reflected.

\section{B. Educational Administration link used in sports}

On College Physical Education in Educational Administration link the use of network technology has a very important significance. Effectively manage the physical education curriculum is the main sport educational administration duties, whether in student course selection, supervision or in the course, also in the statistical Student or sports scores, has a very important value. Many colleges and universities will be the moment of physical education management software application to link sports educational administration, this software is the most prominent advantage is more simple and convenient in operation, can effectively manage student information, faculty, curriculum and other oversight and score inquiry link. By Sports Network technology to educational administration, it is possible to achieve a strict management system, to promote network management students in the process of information security can be effectively guaranteed. More convenient aspects of educational administration courses, course selection, students, and performance management, the arrangements for managing the network structure, are able to get very specific arrangements, not only to get the university to enhance management efficiency, but also allows students to log on during query and fast.

\section{Applied to the student evaluation system}

In Universities Sports Teaching Evaluation System on student learning technology that allows a large degree to enhance statistical efficiency. By means of network technology is not capable of a very orderly comprehensive performance evaluation system set up so that students will be able to unify a good record in physical education courses, the curriculum so that the accuracy of the records are protected, teachers can effectively register on each lesson every good student of the class situation. Student teacher evaluation system is only able to log in to the system maintenance and management, so that the system can be manipulated independently, so you can make typing information security is guaranteed, there is no password can not log into the system, so the system will not be able to content and modify the information. Between student achievement and confirmation of recording, enable regular student achievement and overall performance to summarize and assess the work more convenient and faster. Compared with traditional teaching, the means of network technology to evaluate students' overall achievement, the result of the evaluation out having more accuracy and comprehensiveness, but also allow statistical computation time be reduced to a large extent, to promote work efficiency upgrade.

\section{Summary}

All in all, in College Physical Education learning technology, as opposed to more traditional sports teaching advantages, not only allows students to sports knowledge source structure and learning improved a great deal, but also effectively promote students' sports learning ability training and lifelong learning habits. While the asynchronous nature of teaching and modern teaching methods of online education technology, exploration teaching mode, in-depth education reform has a very important role in promoting effect. In short, the organizational form of teaching science to 
explore, be enhanced so that the quality of teaching is the main direction of the development of teaching sports network, but also its lies.

\section{REFERENCE:}

[1] Liu Peng, Zhang Meng. Application of Computer Network in College Sports Dance Teaching [J]. Gansu Lianhe University (Natural Science), 2011,01: 120-125.

[2] Chan Chongjiang, Chen Xiaohua study [J]. Application of Modern Educational Technology in PE Teaching in Hubei Sports Science, 2011,02: 233-235.

[3] Li Yanan. theory of modern educational technology to optimize University of Physical Education Research [J]. SPORT SCIENCE \& TECHNOLOGY, 2011,07: 53-54 + 92.

[4] Pan Yumei. Modern Educational Technology Strategies in College Physical Teaching of [J] contemporary sports science and technology, 2014,30: $58+60$.

[5] He Weizhen. Modern Educational Technology Application Status and Strategies of PE Teaching Tan Yufang Hengyang City [J]. Modern Sports Science, 2015,07: 171-172.

[6] Wang Yunsheng. Exploration and Research Network of Educational Technology College Physical Education Integration [J]. Chinese education technology and equipment, 2015,14: 153-154. 